\title{
Self-incompatibility Expression in Self-compatible Almond Genotypes May Be Due to Inbreeding
}

\author{
José Manuel Alonso and Rafael Socias i Company ${ }^{1}$ \\ Unidad de Fruticultura, Centro de Investigación y Tecnología Agroalimentaria de Aragón, Apartado \\ 727, 50080 Zaragoza, Spain
}

\begin{abstract}
Additional Index words. Prunus amygdalus, pollen tube growth, breeding
Abstract. Pollen tube growth after selfing was studied in four almond (Prunus amygdalus Batsch) families derived from crosses between self-compatible 'Tuono' and self-incompatible 'Ferragnès' and 'Ferralise' in both directions, in order to ascertain the phenotypic expressions of the different genotypes. A differential expression of self-compatibility was observed in the seedlings of the different families. The genetic self-compatible offspring of 'Ferralise' showed a lower percentage of pistils with pollen tubes at the style base and a lower number of pollen tubes at the pistil base after self-pollination than those observed in the self-compatible offspring of 'Ferragnès'. This low level of self-compatibility expression observed in some 'Ferralise' seedlings may be due to the inbreeding present in 'Ferralise'. As a consequence, caution must be taken in almond breeding to avoid the increase of inbreeding by the utilization of related parents and to diversify the sources of self-compatibility, at present mostly limited to 'Tuono.'
\end{abstract}

Most commercial almond cultivars are self-incompatible, possessing a gametophytic self-incompatibility system (Socias i Company et al., 1976), resulting in the arrest of pollen tube growth in the middle third of the style (de Nettancourt, 1977). As the commercial part of the almond fruit is a seed, both adequate pollination and efficient ovule fertilization are required for acceptable crops. However, obligate cross-pollination creates many management and production problems in almond and are being solved by the development of new self-compatible cultivars in most almond breeding programs (Socias i Company, 1990). Selfcompatibility in almond is due to the presence of a $S_{f}$ allele (Socias i Company and Felipe, 1988). This allele seems to function as a stylar part mutant because the product coded by it in the style lacks ribonuclase activity (Bošković et al., 1999).

Pollination efficiency in self-compatible genotypes implies a similar pollen tube growth rate both for self- and cross-pollination (Socias i Company and Alonso, 2004). However, some pollination trials have shown discrepancies in the growth of the two types of pollen (Ben Njima and Socias i Company, 1995), although the only explanation given has been a differential level of self-compatibility expression in some genotypes.

'Ferragnès' and 'Ferralise' are two cross-incompatible almond cultivars originating from the French breeding program (Grasselly and Crossa-Raynaud, 1980). Their cross-incompatibility has been explained by the fact that they share common $S$ alleles, $S_{l} S_{3}$, which are identical by descent (Crossa-Raynaud and Grasselly, 1985). Thus, their compatibility behavior when pollinated by the same pollen or when being used as pollinators for the same cultivar would be expected to be identical (Socias i Company and Felipe, 1994). However, transmission of self-compatibility to the offspring of these two cultivars when pollinated by 'Tuono' has shown to be very different (Grasselly et al., 1985). 'Tuono' is a self-compatible cultivar with $S_{l} S_{f}$ genotype (Crossa-Raynaud and Grasselly, 1985), thus sharing one allele with these two cultivars probably identical

Received for publication 18 Feb. 2005. Accepted for publication 7 May 2005. This research was supported by the Spanish project CICYT AGL2001-1054C03-02. JMA acknowledges a scholarship grant from the Instituto Nacional de Investigación y Tecnología Agraria y Alimentaria (INIA). Technical assistance by A. Escota, J. Búbal, and J.M. Ansón is highly appreciated.

'Corresponding author; e-mail rsocias@aragon.es. by descent because the $S_{l}$ allele of 'Ferragnès' and 'Ferralise' has been inherited from 'Cristomorto', a cultivar which originated in the same Italian region of Puglia as 'Tuono'.

The observations of Grasselly et al. (1985) were based on fruit sets of seedlings obtained from the different crosses, but their real genotype was unknown. Their genotype determination showed discrepancies between the genotype and the phenotype previously deduced from fruit set in some seedlings (Duval et al., 2001).

'Ferralise' is an inbred almond cultivar (Lansari et al., 1994), as coming from the cross of two full sibs, 'Ferragnès' and 'Ferraduel'. Inbreeding symptoms have appeared in several almond progenies, expressed as a general reduction of vigour (Grasselly and Olivier, 1988). This fitness reduction might also affect pollen tube growth. Thus, our objective was to assess the phenotypic expression of self-compatibility through the level of pollen tube growth in all the possible progenies from the crosses of the selfcompatible cultivar 'Tuono' by 'Ferralise' as well as by 'Ferragnès', in order to ascertain the possible differential effect of 'Ferralise' in the expression of self-compatibility in its offspring.

\section{Materials and Methods}

Plant material. A total amount of 169 seedlings from four progenies obtained from the crosses of 'Tuono' $\left(S_{l} S_{f}\right.$ genotype) by 'Ferragnès' and 'Ferralise' $\left(S_{1} S_{3}\right)$ and their reciprocals were studied (Table 1). The progenies belong to the almond breeding program of the Unidad de Fruticultura from the Centro de Investigación y Tecnología Agroalimentaria de Aragón (CITA) aiming to obtain new self-compatible and late-blooming cultivars. The genotype of each seedling had been previously determined by the analysis of their stylar S-RNases (Bošković et al., 1997) and by the partial amplification of the $S$-genes by PCR (Channuntapitat et al., 2001, 2003).

Phenotype determination By POllen tube growth. Throughout blooming of the years 1998-2003, depending on the availability of buds and time, each seedling was studied during three years. A minimum of 20 flower buds at stage D (Felipe, 1977), just before flower opening, were collected from every progeny seedling, emasculated in the laboratory and placed in a tray with a semi-rigid plastic mesh allowing the contact of the flower peduncles with the tray water to prevent dehydration. At the same time the anthers 
were removed from the emasculated flowers and allowed to dry for $48 \mathrm{~h}$, and their pollen was used to self-pollinate the pistils in the tray. This method of pollen tube growth study has been shown to maintain the compatibility relationships of each cross tested (Socias i Company, 2001). The samples were collected $96 \mathrm{~h}$ after pollination, time enough for the compatible pollen tubes to reach the style base at laboratory temperature (Socias i Company et al., 1976), autoclaved for $20 \mathrm{~min}$ at a pressure of $1.2 \mathrm{~kg} \cdot \mathrm{cm}^{-2}$ in a small glass bottle containing $5 \mathrm{~mL}$ of $5 \%$ solution of $\mathrm{Na}_{2} \mathrm{SO}_{3}$ and maintained at $4{ }^{\circ} \mathrm{C}$ until observation.

For microscopic observation, a minimum of 12 pistils were prepared by dissecting the pistils and leaving only the transmitting tissue through which pollen tubes grow and by removing the ovary. Pollen tube growth was assessed in an UV fluorescence Leitz Ortholux II microscope (Leitz, Wetzler, Germany) with illumination from an Osram HBO 200 W/4 mercury lamp (Osram $\mathrm{GmbH}$, Munich, Germany), by fluorescence of the callose deposits of the pollen tubes by staining with a solution of $0.1 \%$ aniline blue in $0.1 \mathrm{~N}$ potassium phosphate after squashing the pistils (Linskens and Esser, 1957).

The percentage of pistils showing self-pollen tubes at the style base and the mean number of self-pollen tubes at the style base were recorded in each seedling with data of at least 3 years. These values were used for phenotype determination because they have shown to be good criteria to differentiate the phenotypes and classify them following a defined criterion, as Bertin (1993) has shown when reviewing angiosperm self-fertilization. When more than $50 \%$ of pistils showed self-pollen tubes at the style base, the plant was considered to be self-compatible. When this percentage was higher than $75 \%$, the plant was considered to be highly self-compatible. On the other hand, plants with $<25 \%$ of pistils with self-pollen tubes at the style base were considered to be self-incompatible, although in most of the self-incompatible plants $<5 \%$ of pistils showed pollen tubes at their base. The plants with a percentage of pistils between $25 \%$ and $50 \%$ of pistils with self-pollen tubes at the style base were classified as of doubtful phenotype. Similarly, phenotypes were classified according to the mean number of self pollen tubes observed at the style base. The ranges adopted were: no pollen tubes, less than one pollen tube, between one and three pollen tubes, and more than three pollen tubes.

Statistical analysis. Analysis of variance was applied to the combined results of all years of study (3 years for each seedling, or more in the case of doubtful phenotypes).

\section{Results}

Pollen tube Growth AND Phenotype. Usually, pollen tubes stop their growth in the middle third of the style in self-incompatible genotypes, but they grow through the style and some reach the style base in the self-compatible ones to get into the ovary (Fig. 1). However, although self-compatibility is a genetically qualitative trait in almond (Socias i Company, 1998), its expression has been shown to be variable and dependent on the genotype (Socias i Company et al., 2004). As a consequence, quantification of self-compatibility expression requires several years of data on selfing behavior.

The microscopic observation of self-pollen tube growth showed its high variability among the seedlings of these segregant progenies and allowed the phenotypic classification of seedlings whose genotype was already known (Table 1). As a whole, the self-compatible genotypes with 'Ferragnès' parentage had a

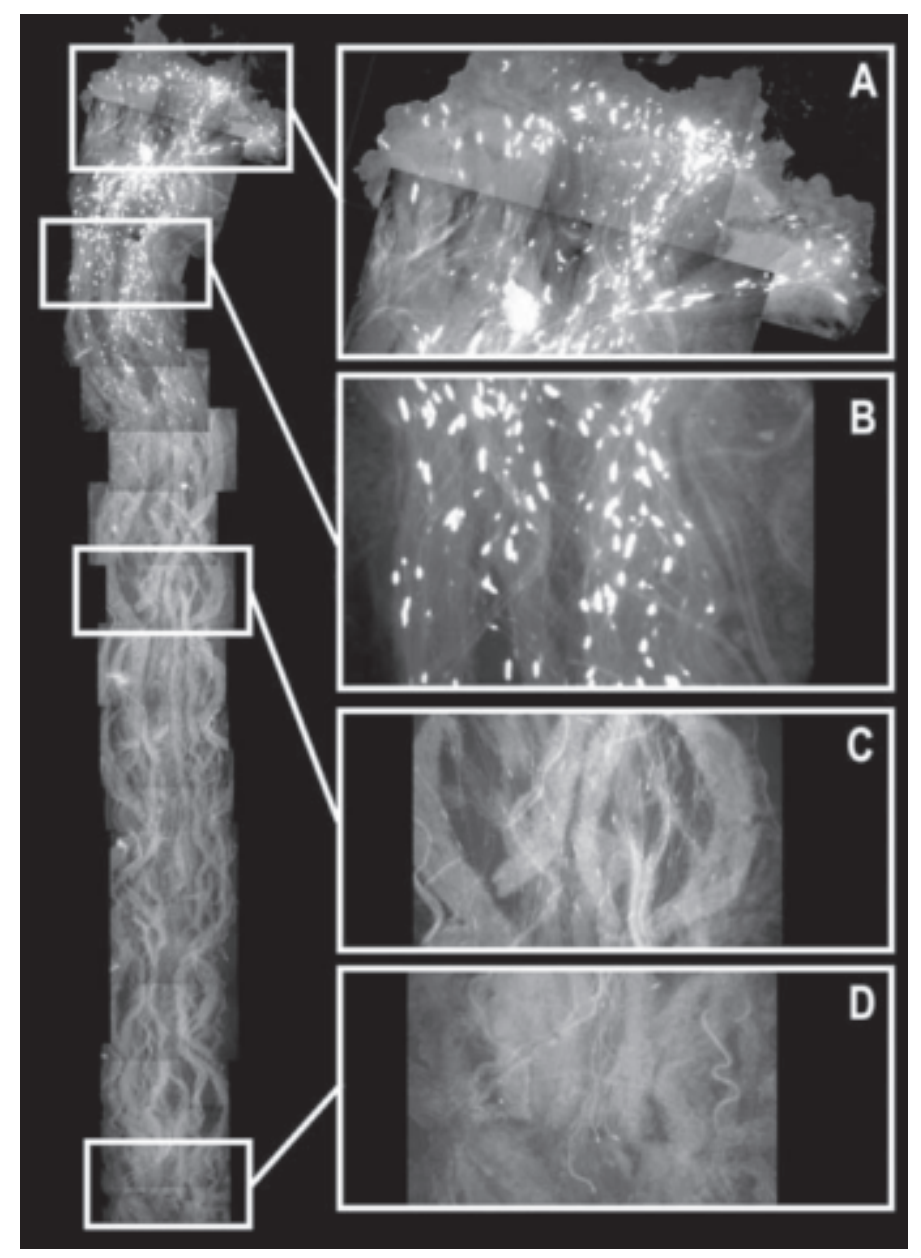

Fig. 1. Microscopic observation of the squash of an almond pistil with a high number of pollen tubes at the style base: (A) good penetration of pollen tubes in the stigma tissues; (B) massive growth of pollen tubes in the upper third of the style; (C) self-compatible pollen tubes continue their growth; (D) the most vigorous pollen tubes grow across the style base and consequently penetrate into the ovary.

significant higher percentage of pistils with pollen tubes at the style base (78.15\% vs. $64.41 \%)$ and a significant higher number of pollen tubes at their base (3.51 vs. 2.43) than self-compatible seedlings with 'Ferralise' parentage. These differences are mainly due to the results obtained in the progenies in which 'Tuono' was the male parent, where the differences were also significant, whereas in the progenies in which 'Tuono' was the female parent the differences were not significant, probably due to the low number of seedlings available.

The differences in the percentage of pistils and in the mean number of pollen tubes were not significant in the self-incompatible genotypes, with $6.16 \%$ of pistils and 0.08 pollen tubes for 'Ferragnès' seedlings compared to $5.76 \%$ of pistils and 0.16 pollen tubes for 'Ferralise' seedlings. In addition, the presence of these self-pollen tubes at the style base is merely accidental and, when it occurs, only a single weak pollen tube is observed.

The phenotype distribution was expected to be similar in the progenies of 'Ferragnès' and 'Ferralise' because of their identical $S$ alleles. However, according to the percentage of pistils (Table 2 ), the combined percentage of seedlings with self-compatible and highly self-compatible phenotype observed in the progeny 'Tuono' $x$ 'Ferragnès' was higher than in the progeny 'Tuono' $x$ 'Ferralise' (60.6\% vs. $14.3 \%)$. 
Table 1. Comparison, between the offspring of two self-incompatible parents in almond, of the mean number of pollen tubes at the style base and the percentage of pistils with pollen tubes at their bases, by genotype.

\begin{tabular}{|c|c|c|c|c|c|c|c|}
\hline \multirow[b]{2}{*}{ Family } & \multirow[b]{2}{*}{$\begin{array}{c}\text { Plants } \\
\text { (no.) }\end{array}$} & \multicolumn{3}{|c|}{ Self-compatible genotypes } & \multicolumn{3}{|c|}{ Self-incompatible genotypes } \\
\hline & & $\begin{array}{c}\text { Plants } \\
\text { (no.) }\end{array}$ & $\begin{array}{l}\text { Pollen tubes } \\
\text { at the style } \\
\text { base (no.) }\end{array}$ & $\begin{array}{c}\text { Pistils with } \\
\text { pollen tubes } \\
\text { at their base } \\
(\%)\end{array}$ & $\begin{array}{c}\text { Plants } \\
\text { (no.) }\end{array}$ & $\begin{array}{l}\text { Pollen tubes } \\
\text { at the style } \\
\text { base (no.) }\end{array}$ & $\begin{array}{c}\text { Pistils with } \\
\text { pollen tubes } \\
\text { at their base } \\
(\%)\end{array}$ \\
\hline 'Ferragnès' seedlings & 62 & 49 & 3.51 & 78.15 & 13 & 0.08 & 6.16 \\
\hline 'Ferralise' seedlings & 107 & 92 & 2.43 & 64.41 & 15 & 0.16 & 5.76 \\
\hline $\mathrm{F}^{\mathrm{z}}$ & & & $16.52^{* * *}$ & $10.37^{* * *}$ & & $0.29^{\mathrm{NS}}$ & $0.01^{\mathrm{NS}}$ \\
\hline 'Tuono' x 'Ferragnès' & 33 & 20 & 3.36 & 74.64 & 13 & 0.08 & 6.16 \\
\hline 'Tuono' x 'Ferralise' & 21 & 6 & 1.99 & 53.67 & 15 & 0.16 & 5.76 \\
\hline $\mathrm{F}^{\mathrm{z}}$ & & & $3.99^{\mathrm{NS}}$ & $3.52^{\mathrm{NS}}$ & & $0.29^{\mathrm{NS}}$ & $0.01^{\mathrm{NS}}$ \\
\hline 'Ferragnès' x 'Tuono' & 29 & 29 & 3.61 & 80.58 & --- & & \\
\hline 'Ferralise' x 'Tuono' & 86 & 86 & 2.46 & 65.15 & --- & & \\
\hline $\mathrm{F}^{\mathrm{z}}$ & & & $12.48^{* * *}$ & $8.83^{* *}$ & & & \\
\hline
\end{tabular}

Table 2. Distribution of seedlings in each of four almond families studied according to the percentage of pistils with self-pollen tubes at their style bases.

\begin{tabular}{|c|c|c|c|c|c|c|c|c|c|c|c|}
\hline \multirow[b]{2}{*}{ Family } & \multirow[b]{2}{*}{ Genotype } & \multicolumn{2}{|c|}{ Total seedlings } & \multicolumn{2}{|c|}{$\begin{array}{c}\text { Self-incompatible } \\
(<25 \%)\end{array}$} & \multicolumn{2}{|c|}{$\begin{array}{c}\text { Doubtful } \\
(25 \% \text { to } 50 \%) \\
\end{array}$} & \multicolumn{2}{|c|}{$\begin{array}{c}\text { Self-compatible } \\
(50 \% \text { to } 75 \%)\end{array}$} & \multicolumn{2}{|c|}{$\begin{array}{c}\text { Highly self- } \\
\text { compatible } \\
(>75 \%)\end{array}$} \\
\hline & & (no.) & $(\%)$ & (no.) & $(\%)^{\mathrm{Z}}$ & (no.) & $(\%)^{\mathrm{z}}$ & (no.) & $(\%)^{\mathrm{z}}$ & (no.) & $(\%)^{\mathrm{z}}$ \\
\hline \multirow{2}{*}{ 'Tuono' x 'Ferragnès' } & $S_{1} S_{3}$ & 13 & 39.4 & 13 & 100 & 0 & 0 & 0 & 0 & 0 & 0 \\
\hline & $S_{f} S_{3}$ & 20 & 60.6 & 0 & 0 & 0 & 0 & 9 & 45.0 & 11 & 55.0 \\
\hline \multirow{2}{*}{ 'Tuono' x 'Ferralise' } & $S_{1} S_{3}$ & 15 & 71.4 & 14 & 93.3 & 1 & 6.6 & 0 & 0 & 0 & 0 \\
\hline & $S_{f} S_{3}$ & 6 & 28.6 & 3 & 50.0 & 0 & 0 & 1 & 16.6 & 2 & 33.3 \\
\hline \multirow{3}{*}{ 'Ferragnès' x 'Tuono' } & $S_{f} S_{l}$ & 18 & 62.1 & 0 & 0 & 1 & 5.6 & 5 & 27.8 & 12 & 66.6 \\
\hline & $S_{f} S_{3}$ & 11 & 37.9 & 0 & 0 & 0 & 0 & 3 & 27.3 & 8 & 72.7 \\
\hline & $S_{f} S_{-}$ & 29 & 100.0 & 0 & 0 & 1 & 3.4 & 8 & 27.9 & 20 & 69.0 \\
\hline \multirow{3}{*}{ 'Ferralise' x 'Tuono' } & $S_{f} S_{l}$ & 44 & 51.2 & 3 & 6.8 & 5 & 11.4 & 13 & 29.5 & 23 & 52.3 \\
\hline & $S_{f} S_{3}$ & 42 & 48.8 & 5 & 11.9 & 5 & 11.9 & 10 & 23.8 & 22 & 52.4 \\
\hline & $S_{f} S_{-}$ & 86 & 100.0 & 8 & 9.3 & 10 & 11.6 & 23 & 26.7 & 45 & 52.3 \\
\hline
\end{tabular}

zPercentages refer to each genotype within each family.

When phenotypic self-compatibility was assessed according to the mean number of self-pollen tubes at the style base (Table 3 ), a similar percentage of the self-incompatible genotypes $\left(S_{1} S_{3}\right)$ from the crosses 'Tuono' $x$ 'Ferragnès' (61.5\%) and 'Tuono' $x$ 'Ferralise' $(60.0 \%)$ did not show any pollen tubes at the style base, whereas the rest were doubtful with a mean lower than one pollen tube per pistil.

On the other hand (Table 3), more than $60 \%$ of the self-compatible genotypes $(S S)$ with 'Ferragnès' parentage showed more than three self-pollen tubes at the style base per style $(60.0 \%$ in 'Tuono' $x$ 'Ferragnès' and $62.1 \%$ in 'Ferragnès' $x$ 'Tuono'), whereas in those with 'Ferralise' parentage this proportion was only of 33\% (33.3\% in 'Tuono' $x$ 'Ferralise' and 33.7\% in 'Ferralise' $x$ 'Tuono').

There was an agreement between the two criteria of phenotype classification: the plants classified as self-compatible according to the percentage of pistils with pollen tubes at their base showed more than one pollen tube at the style base and the highly selfcompatible plants according to the first criterion showed in most of the cases more than three pollen tubes at the style base.

EXISTENCE OF SEEDLINGS WITH THE $\boldsymbol{S}_{f}$ ALLELE AND A SELF-INCOMPATIBLE PHENOTYPE. The $S$ genotype of each seedling was already known, with a full agreement between the genotypes deduced by the stylar $S$-RNase analysis and by the partial amplification of the $S$-genes by PCR (data not shown). However, some seedlings possessing the $S_{f}$ allele and, therefore, supposedly self-compatible, showed the inability of their pollen tubes to reach the ovary in all cases. These plants, showing a physiologic self-incompatibility and a genetic self-compatibility, are all seedlings of 'Ferralise', while in all seedlings of 'Ferragnès' there was a full agreement between the $S_{f}$ allele presence determined by PCR analysis and a self-compatible phenotype. The plants whose phenotype according to the percentage of pistils with self-pollen tubes at the style base (Table 2) was not in agreement with their $S$ genotype amounted to $50.0 \%$ of the 'Tuono'x 'Ferralise' progeny with $S_{3} S_{f}$ genotype (three seedlings), and to $11.9 \%$ with $S_{3} S_{f}$ genotype (five seedlings) and to $6.8 \%$ with $S_{l} S_{f}$ genotype (three seedlings) in the 'Ferralise' $x$ 'Tuono' progeny. In this last family, where all the seedlings were expected to show a self-compatible phenotype, 9.3\% of them showed a clear self-incompatible phenotype whereas in the 'Ferragnès' $x$ 'Tuono' progeny, all seedlings were clearly self-compatible. In addition, the self-compatible genotypes showing a self-incompatible phenotype are characterized by showing a mean number of self-pollen tubes at the style base lower than one. Also, $11.6 \%$ of 'Ferralise' $x$ 'Tuono' progeny showed a doubtful phenotype, whereas in 'Ferragnès' $x$ 'Tuono' progeny this percentage was only of $3.4 \%$. 
Table 3. Distribution of seedlings in each of four almond families studied according to the mean number of self-pollen tubes at their style bases.

\begin{tabular}{|c|c|c|c|c|c|c|c|c|c|c|c|}
\hline \multirow[b]{3}{*}{ Family } & \multirow[b]{3}{*}{ Genotype } & & & \multicolumn{8}{|c|}{ Seedlings with a mean no. of self-pollen tubes } \\
\hline & & \multicolumn{2}{|c|}{ Total seedlings } & \multicolumn{2}{|c|}{0} & \multicolumn{2}{|c|}{$<1$} & \multicolumn{2}{|c|}{1 to 3} & \multicolumn{2}{|c|}{$>3$} \\
\hline & & (no.) & $(\%)$ & (no.) & $(\%)^{\mathrm{z}}$ & (no.) & $(\%)^{\mathrm{z}}$ & (no.) & $(\%)^{\mathrm{z}}$ & (no.) & $(\%)^{\mathrm{z}}$ \\
\hline \multirow{2}{*}{ 'Tuono' x 'Ferragnès' } & $S_{1} S_{3}$ & 13 & 39.4 & 8 & 61.5 & 5 & 38.5 & 0 & 0 & 0 & 0 \\
\hline & $S_{f} S_{3}$ & 20 & 60.6 & 0 & 0 & 0 & 0 & 8 & 40.0 & 12 & 60.0 \\
\hline \multirow{2}{*}{ 'Tuono’ x ‘Ferralise' } & $S_{1} S_{3}$ & 15 & 71.4 & 9 & 60.0 & 6 & 40.0 & 0 & 0 & 0 & 0 \\
\hline & $S_{f} S_{3}$ & 6 & 28.6 & 0 & 0 & 3 & 50.0 & 1 & 16.6 & 2 & 33.3 \\
\hline \multirow{3}{*}{ 'Ferragnès' $\mathrm{x}$ 'Tuono' } & $S_{f} S_{1}$ & 18 & 62.1 & 0 & 0 & 1 & 5.6 & 7 & 38.8 & 10 & 55.5 \\
\hline & $S_{f} S_{3}$ & 11 & 37.9 & 0 & 0 & 0 & 0 & 3 & 27.3 & 8 & 72.7 \\
\hline & $S_{f} S_{-}$ & 29 & 100.0 & 0 & 0 & 1 & 3.4 & 10 & 34.5 & 18 & 62.1 \\
\hline \multirow{3}{*}{ 'Ferralise' x ‘Tuono' } & $S_{f} S_{1}$ & 44 & 51.2 & 0 & 0 & 8 & 18.2 & 22 & 50.0 & 14 & 31.8 \\
\hline & $S_{f} S_{3}$ & 42 & 48.8 & 3 & 7.1 & 5 & 11.9 & 19 & 43.2 & 15 & 35.7 \\
\hline & $S_{f} S_{-}$ & 86 & 100.0 & 3 & 3.5 & 13 & 15.1 & 41 & 47.6 & 29 & 33.7 \\
\hline
\end{tabular}

${ }^{2}$ Percentages refer to each genotype within each family.

\section{Discussion}

QUALITY OF SELF-COMPATIBILITY. The observation of the pollen tube growth after self-pollination allows not only the differentiation of the self-compatible plants and the determination of the phenotype frequencies, but also the establishment of the quality of the self-compatibility expression and the possible interest of each plant of the breeding program for this trait. Although ovule fertilization may take place with a single pollen tube entering the ovary (Pimienta and Polito, 1983), in some cases pollen tube growth becomes chaotic before or after the obturator, resulting in the failed fertilization of the primary ovule and subsequent fruit abortion (Cousin and El Maataoui, 1998). Consequently, the probability of a successful fertilization increases with a high number of pollen tubes reaching the style base.

Self-compatibility level has an agronomic implication, since the percentage of pistils with pollen tubes at their style base, the number of pollen tubes reaching the ovary, and the homogeneity of these data, may be used as selection criteria in an almond breeding program for self-compatibility, as all these traits would induce a higher initial fruit set and, consequently, a better yield level. In the ensemble of crosses, 'Ferragnès' seedlings had more pollen tubes at the style base than 'Ferralise' seedlings, and this behavior may have a genetic basis because the same behavior was observed in pollinations carried out with 'Tuono', 'Ferragnès', and 'Ferralise' (Socias i Company and Alonso, 2004), and may be due to lower vigor in the pistil and the pollen of the 'Ferralise' seedlings due to inbreeding transmitted by this cultivar.

It has been possible to identify some phenotypes showing very high self-compatibility judged by the percentage of pistils with pollen tubes and the number of pollen tubes, thus showing a special interest in the breeding program because almond requires a very high initial fruit set in order to obtain acceptable yields due to the small size of the fruit (Godini, 2002; Kester and Griggs, 1959).

Parental EFFECT ON SELF-COMPaTibility EXPRESSION. In progenies where 'Tuono' was the female parent, and therefore segregating for self-compatibility, opposite phenotypic proportions were obtained between the two pollen parents: in the family 'Tuono' $x$ 'Ferragnès' the number of self-compatible phenotypes was slightly higher than the number of self-incompatible ones, as Socias i Company and Felipe (1988) and Dicenta and García (1993) had observed in two other 'Tuono' X 'Ferragnès' progenies, whereas in the family 'Tuono' $x$ 'Ferralise' the number of self-compatible phenotypes was about $15 \%$ of the progeny. Seedlings with self-incompatible phenotype and self-compatible genotype only appeared in the 'Ferralise' offspring, agreeing with the observations of Grasselly (1985).

When comparing the results of the phenotypic observations with the $S$ genotype of each individual, it was found that the presence of the $S_{f}$ allele did not necessarily imply a self-compatible phenotype. This was the case in some seedlings deriving from 'Ferralise', but not in any seedlings deriving from 'Ferragnès'. About one-tenth of the seedlings from the family 'Ferralise' $x$ 'Tuono', where all genotypes included the $S_{f}$ allele, showed a sound physiological self-incompatible phenotype during all years of observation, a disagreement never previously reported. This discrepancy between genotype and phenotype is also manifested in some seedlings from the reciprocal cross, where genotypic segregation was expected.

BREEDING CONCLUSIONS. Although the reduction in the number of pollen tubes in the style in many species may be due to morphological and biochemical factors (Hormaza and Herrero, 1996; Pimienta et al., 1983; Sedgley, 1976), and pistil response to pollination may not be only genetically controlled (Ortega et al., 2002), the physiological self-incompatibility observed in some of these inbred seedlings may be due to another type of control, namely inbreeding. Inbreeding is a genetic particularity affecting both the morphology and biochemistry of the affected genotypes and representing a particular problem in almond, a species very sensitive to inbreeding and whose genetic pool has been gradually reduced. The utilization of unrelated heterozygous self-compatible parents in the breeding programs has been suggested to obtain homozygous self-compatible genotypes, thus obviating the problems raised by inbreeding in almond (Ortega and Dicenta, 2003).

The self-incompatible phenotype observed in 'Ferralise' seedlings possessing the $S_{f}$ allele is a clear example of the importance of assessing the phenotype of each individual by the observation of pollen tube growth after selfing in order to know the quality of its self-compatibility. The single knowledge of the genotype is not enough to rate a plant as self-compatible or self-incompatible.

\section{Literature Cited}

Ben Njima, N. and R. Socias i Company. 1995. Characterization of some self-compatible almonds. I. Pollen tube growth. HortScience 30:318-320.

Bertin, R. 1993. Incidence of monoecy and dichogamy in relation to self-fertilization in angiosperms. Amer. J. Bot. 80:557-560. 
Bošković, R., K.R. Tobutt, I. Batlle, and H. Duval. 1997. Correlation of ribonuclease zymograms and incompatibility genotypes in almond. Euphytica 97:167-176.

Bošković R., K.R. Tobutt, H. Duval, I. Batlle, F. Dicenta, and F.J. Vargas. 1999. A stylar ribonuclease assay to detect self-compatible seedlings in almond progenies. Theor. Appl. Genet. 99:800-810.

Channuntapipat, C., M. Sedgley, and G. Collins. 2001. Sequences of the cDNAs and genomic DNAs encoding the $\mathrm{S} 1, \mathrm{~S} 7, \mathrm{~S} 8$ and $\mathrm{Sf}$ alleles from almond, Prunus dulcis. Theor. Appl. Genet. 103:1115-1122.

Channuntapipat, C., M. Wirthensohn, S.A. Ramesh, I. Batlle, P. Arús, M. Sedgley, and G. Collins. 2003. Identification of incompatibility genotypes in almond (Prunus dulcis Mill.) using specific primers based on the introns of the S-alleles. Plant Breeding 122:164-168.

Cousin, M. and M. El Maataoui. 1998. Female reproductive organs in self-compatible almond (Prunus dulcis (Mill.) D. A. Webb) Lauranne and fertilization patterns. Scientia Hort. 72:287-297.

Crossa-Raynaud, P. and C. Grasselly. 1985. Éxistence de groupes d'interstérilité chez l'amandier. Options Méditerranéennes 85/ I:43-45.

de Nettancourt, D. 1977. Incompatibility in angiosperms. Springer Verlag, Heidelberg.

Dicenta, F. and J.E. García. 1993. Inheritance of self-compatibility in almond. Heredity 70:313-317.

Duval, H., A. Boutard, and M. Faurobert. 2001. Analysis of stylar ribonucleases (S-RNases) in an almond progeny of 'Ferralise' $\mathrm{X}$ 'Tuono.' Cahiers Options Méditerranéennes 56:91-94.

Felipe, A.J. 1977. Almendro: Estados fenológicos. Información Técnica Económica Agraria 27:8-9.

Godini, A. 2002. Almond fruitfulness and role of self-fertility. Acta Hort. 591:191-203.

Grasselly, C. 1985. Avancement du programme "autocompatibilité" chez 1’amandier. Cahiers Options Méditerranéennes 85/I:39-41.

Grasselly, C. and P. Crossa-Raynaud. 1980. L'amandier. G.P. Maisonneuve et Larose, Paris, France.

Grasselly, C., P. Crossa-Raynaud, and G. Olivier. 1985. Récents progrès dans l'amélioration génétique de l'amandier. V Colloque de Recherches Fruitières, Bordeaux, 13-14 Nov. 1985, p. 141-155.

Grasselly, C. and G. Olivier. 1988. Phenomènes d'inbreeding dans les descendances issues d'autofecondation chez l'amandier. 7e Colloque du Grempa. Comisión des Communautés Européennes. Rapport EUR 11557:73-78.

Hormaza, J.I. and M. Herrero .1996. Dynamics of pollen tube growth under different competition regimes. Sexual Plant Reproduction 9:153-160.

Kester, D.E. and W.H. Griggs. 1959. Fruit setting in the almond:
The pattern of flower and fruit drop. Proc. Amer. Soc. Hort. Sci. $74: 214-219$.

Lansari, A., D.E. Kester, and A.R. Iezzoni. 1994. Inbreeding, coancestry, and founding clones of almonds of California, Mediterranean shores and Russia. J. Amer. Soc. Hort. Sci. 119:1279-1285.

Linskens, H.F. and K. Esser. 1957. Über eine spezifische Anfärbung der Pollenschläuche im Griffel und die Zahl der Kallosepfropfen nach Selbstung und Fremdung. Naturwissenschaften 44:16-21.

Ortega, E. and F. Dicenta. 2003. Inheritance of self-compatibility in almond: Breeding strategies to assure self-compatibility in the progeny. Theor. Appl. Genet. 106:904-911.

Ortega, E., J. Egea, J.A. Cánovas, and F. Dicenta. 2002. Pollen tube dynamics following half- and fully-compatible pollinations in selfcompatible almond cultivars. Sexual Plant Reproduction 15:47-51.

Pimienta, E. and V.S. Polito. 1983. Embryo sac development in almond (Prunus dulcis (Mill) D. A. Webb) as affected by cross-, self-, and non-pollination. Ann. Bot. 51:469-479.

Pimienta, E., V.S. Polito, and D.E. Kester. 1983. Pollen tube groth in cross- and self-pollinated 'Nonpareil' almond. J. Amer. Soc. Hort. Sci. 108:643-647.

Sedgley, M. 1976. Control by the embryo sac over pollen tube growth in the style of the avocado (Persea americana Mill.). New Phytol. $77: 149-152$.

Socias i Company, R. 1990. Breeding self-compatible almonds. Plant Breeding Rev. 8:313-338.

Socias i Company, R. 1998. Fruit tree genetics at a turning point: The almond example. Theor. Appl. Genet. 96:588-601.

Socias i Company, R. 2001. Differential growth of almond pollen tubes in three environments. Cahiers Options Méditerranéennes 56:59-64.

Socias i Company, R. and J.M. Alonso. 2004. Cross-incompatibility of 'Ferragnès' and 'Ferralise' and pollination efficiency for self-compatibility transmission in almond. Euphytica 135:333-338.

Socias i Company, R., Alonso, J.M. and Gómez Aparisi, J. 2004. Fruit set and productivity in almond as related to self-compatibility, flower morphology and bud density. J. Hort. Sci. Biotechnol. 79:754-758.

Socias i Company, R. and A.J. Felipe. 1988. Self-compatibility in almond: Transmission and recent advances in breeding. Acta Hort. 224:307-317.

Socias i Company, R. and A.J. Felipe. 1994. Cross-incompatibility of 'Ferragnès' and 'Ferralise': Implications for self-compatibility transmission in almond. Acta Hort. 373:153-156.

Socias i Company, R., D.E. Kester, and M.V. Bradley. 1976. Effects of temperature and genotype on pollen tube growth of some self-incompatible and self-compatible almond cultivars. J. Amer. Soc. Hort. Sci. 101:490-493. 